\title{
Project Change Management System
}

\author{
By C. William Ibbs, ${ }^{1}$ Clarence K. Wong, ${ }^{2}$ and Young Hoon Kwak ${ }^{3}$
}

\begin{abstract}
Changes in projects are common and may be deleterious or beneficial-whether you see a change as a conflict or a valuable lesson depends only on your prospective. Project changes affect the cost, the scheduling, and the duration of projects, both directly and indirectly. Despite many articles and much discussion in practice and academic literature, there is a lack of information about systematic approaches to manage project change. This paper introduces a comprehensive project change management system that is founded on five principles: (1) promote a balanced change culture; (2) recognize change; (3) evaluate change; (4) implement change; and (5) continuously improve from lessons learned. By applying this project change management system, project participants can minimize deleterious change and promote beneficial change.
\end{abstract}

\section{INTRODUCTION}

Changes and conflicts in projects, at work, and even in our daily lives are very common (Pinto and Kharbanda 1995). Any additions, deletions, or other revision to project goals and scope are considered to be changes, whether they increase or decrease the project cost or schedule. Most commonly, lack of timely and effective communication, lack of integration, uncertainty, a changing environment, and increasing project complexity are the drivers of project change (Naoum 1994). In addition, these changes may affect other aspects of the performing organization that may have program management implications.

In project management, changes in projects can cause substantial adjustment to the contract duration time, total direct and indirect cost, or both (Tiong 1990; Ibbs 1997; Ibbs et al. 1998). Therefore, project management teams must have the ability to respond to change effectively in order to minimize the impact to the project.

Because changes are common to projects, it is critical to understand that managers confront, embrace, adapt, and use changes to impact positively the situations they face and to recognize changes as growth (Huntoon 1998). Kartam (1996) has suggested that conflict will be minimized when a problem has been studied as early as possible, since the problems can be identified and beneficial changes can be made.

Common project planning tools such as risk analysis can be used to reduce the destructive consequences of

${ }^{1}$ Prof., Dept. of Civ. and Envir. Engrg., Univ. of California, Berkeley, CA 94720. E-mail: ibbs@ce.berkeley.edu

${ }^{2}$ Asst. Proj. Mgr., Saylor Consulting Group, 12 Geary St., Seventh Floor, San Francisco, CA 94108. E-mail: clarence_wong@ hotmail.com

${ }^{3}$ Asst. Prof., Proj. Mgmt. Program, Dept. of Mgmt. Sci., The George Washington Univ., Monroe Hall 403, Washington, DC 20052. E-mail: kwak@gwu.edu

Note. Discussion open until December 1, 2001. To extend the closing date one month, a written request must be filed with the ASCE Manager of Journals. The manuscript for this paper was submitted for review and possible publication on July 18, 2000; revised October 2, 2000. This paper is part of the Journal of Management in Engineering Vol. 17, No. 3, July, 2001. CASCE, ISSN 0742-597X/01/0003/0159-0165/ $\$ 8.00+\$ .50$ per page. Paper No. 22205 . change, because they give insights and predictions to identify possible conflicts (Mallak et al. 1997). Pinto has suggested that good communication can lead to changes that have a positive effect on the project, as managers can learn valuable lessons from the conflict episode (Pinto and Kharbanda 1995).

Before the project is started, one other strategy that can be considered is to think through the project and to use the tools previously described and their output from the study to prevent conflict. Development and implementation of a project change management system before the project commences is a good, proactive step toward constructively managing change.

\section{BACKGROUND}

The Construction Industry Institute (CII) established the Project Change Management Research Team to find a method to avoid or minimize delays, inflated cost, general claims, and even costly litigation associated with project change. The research team hypothesized that significant savings in the total installed cost and schedule of any construction project were achievable by improving the management of changes (CII 1994).

Ibbs summarized the results of the quantitative impacts of project change (Ibbs 1997). During the course of data collection, the research team observed a variety of partial, hodgepodge systems to manage change. After finalizing the analysis of the quantitative impacts, the CII research team developed a vision of a comprehensive, "cradle-tograve" change management system (CMS) (CII 1994).

The algorithm presented in this paper is the result of that collaboration between the 12 members of the CII Project Change Research Team. Both clients and consultants can benefit from the change management system by its efficiency of dealing with changes. On construction projects, consultants would include designers, construction management consultants, and contractors. However, this CMS is designed to be adaptable to projects outside of construction sector that are applying project management tools and techniques, including software development, new product development, and the telecommunications sector as well. 


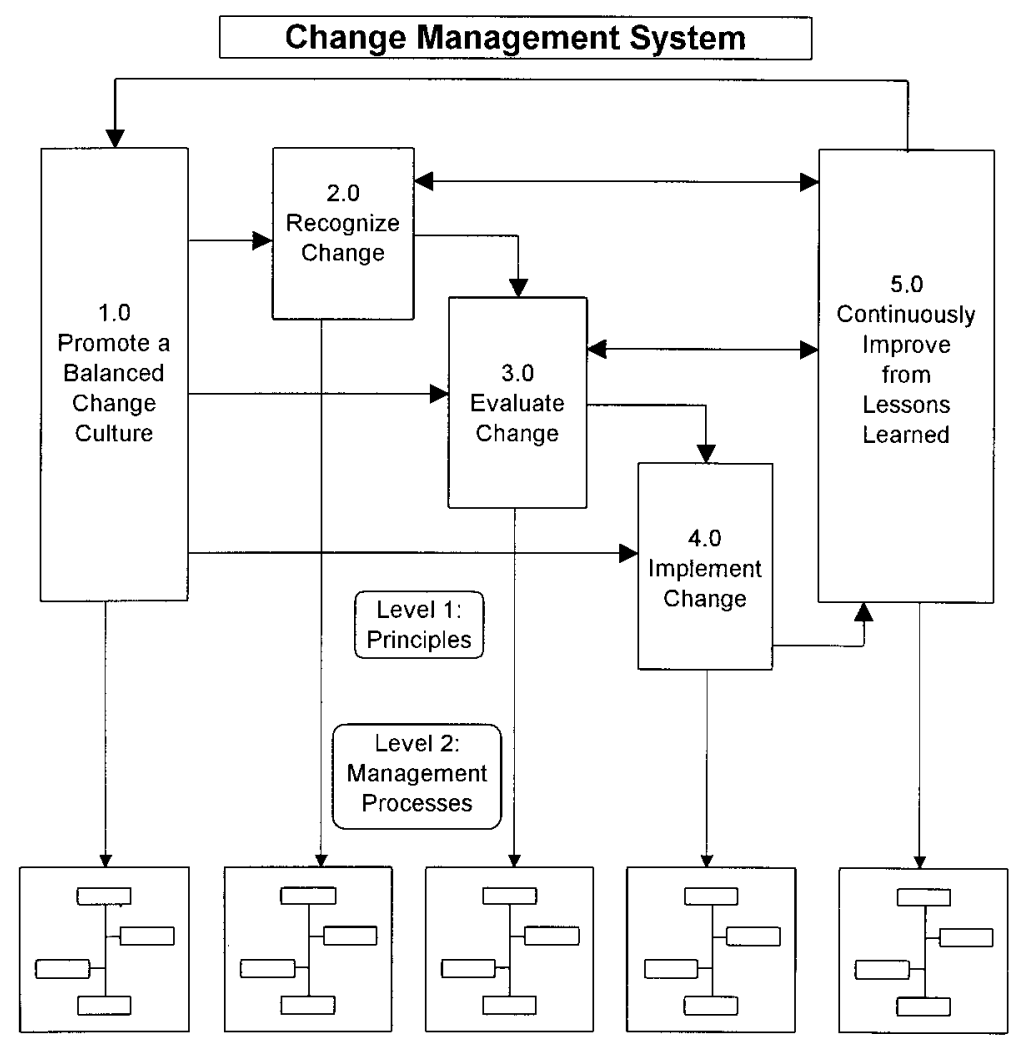

FIG. 1. Change Management System

\section{STRUCTURE OF PROJECT CHANGE MANAGEMENT SYSTEM}

CMS has two levels: a level of starting principles and a detailed level of management processes (Fig. 1). This paper mainly describes the structure of the first level. The first level is founded on five principles: (1) promote a balanced change culture; (2) recognize change; (3) evaluate change; (4) implement change; and (5) continuously improve from lessons learned. Each of these principles works hand-in-hand with the other. In fact, it is necessary for each category to "interact" with the others in order to maximize the function of the system. In this system, it is not necessary that the recognition, the evaluation, and other principles are only applicable to one single project. Rather, the actions, results, and conclusions from using the system on one project may be similar to another project, given that the scopes of the projects are similar.

As a result, cost and delay seen in one project can be minimized if there is either a systematic way to change effectively or a systematic way to compare the conflicts in similar projects. Moreover, decision making is a significant characteristic that occurs in each phase of a project. In almost every stage, decision making is necessary. Often, these decisions will, or can, affect the other tasks that will take place or that are taking place. To make the overall decision-making process effective, project managers and the other personnel of one project need to have a general understanding of other related or similar projects. This underscores the importance of having a good communication and documentation system.

\section{PROMOTE A BALANCED CHANGE CULTURE}

The first principle of effective change management is to promote a balanced change culture (Fig. 2). In this principle, communication and documentation of the critical project success factors between the team members is very important, because they will become part of the scope of the project. In addition, these actions can reduce the possibility of conflicts occurring. Two other concepts should be introduced to the project management team: beneficial changes and detrimental changes. It is very important to encourage and to support the team members that beneficial changes should be encouraged and supported and that detrimental changes should be discouraged and avoided.

Not all changes are bad. Indeed, the notion of value engineering, for example, is that some change is desirable. Beneficial changes, which result from value engineering exercises and can actually help to reduce cost, schedule, or degree of difficulty, are welcomed by the management team, since these changes benefit the project. These beneficial changes not only give an immediate and positive impact, but they also can provide the platform and environment for managers to seek.

On the other hand, detrimental changes are to be minimized. These changes reduce owner value and have a negative impact on a project. Project management teams should beware that detrimental changes are not always recognized as "detrimental" until problems occur. Detrimental changes may occur when there are insufficient alternatives to the problem they present. Therefore, identi- 


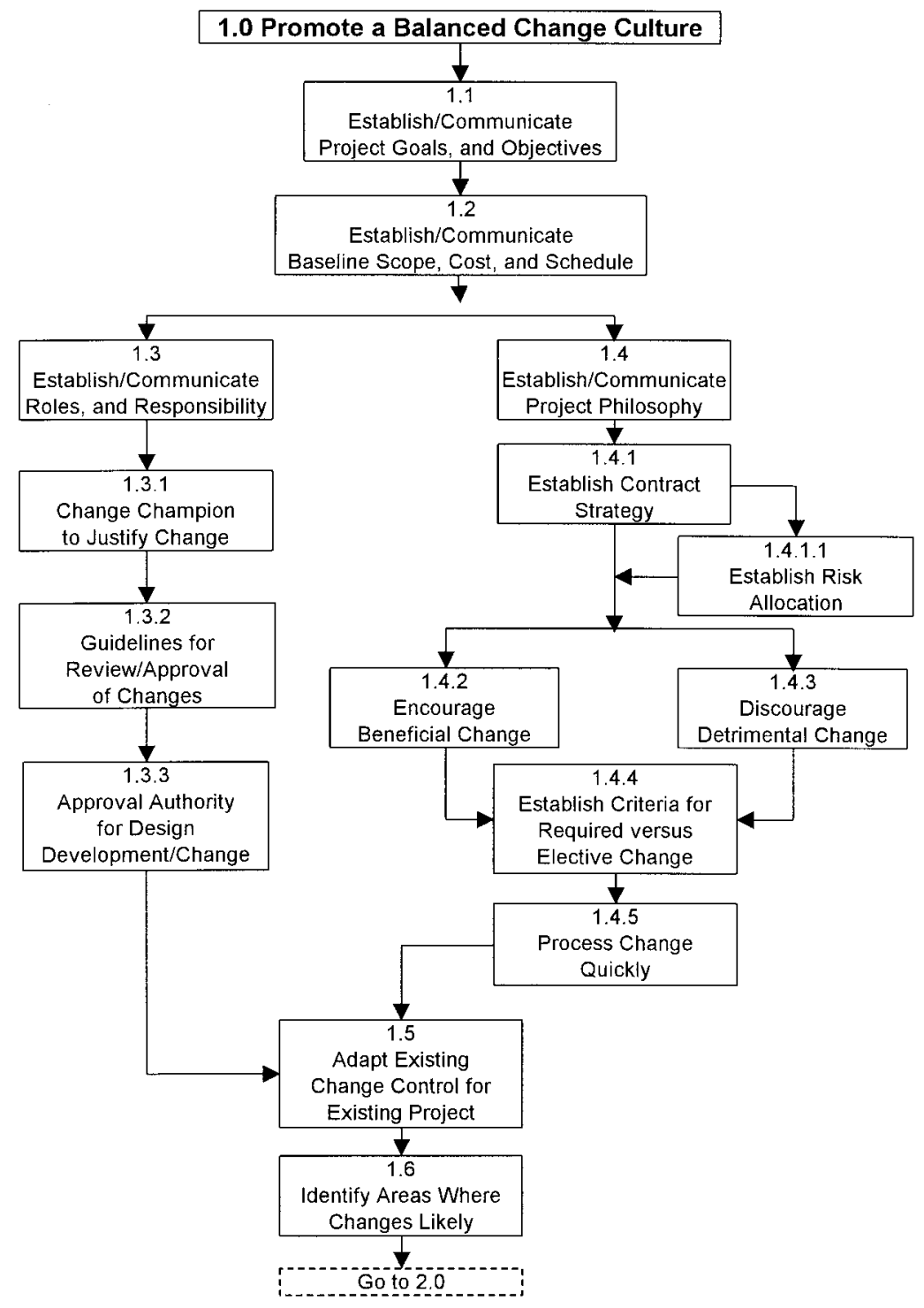

FIG. 2. Promote Balanced Change Culture

fying areas where changes are likely to occur is important, since the team can anticipate changes and prepare reactions to these changes proactively. Of course, the timing of a change often determines if the change is beneficial or detrimental. A suggestion in the early states of a project may be helpful, but that same suggestion later in the project may actually increase project costs and schedule. Although it is unlikely that improvements on the change might not benefit the change a whole lot, the suggestion may protect the remaining portion of the project from the unexpected losses.

\section{RECOGNIZE CHANGE}

The second principle of effective change management is to recognize change (Fig. 3). Similar to the first principle, communications within the team is very important. In this principle, team members are encouraged to open discussion and to identify potential changes. Identifying changes prior to their actual occurrence can help the team to manage change better and earlier in the project life cycle.

After potential changes have been recognized, the team members should determine whether these changes are "required" or "elective." A required change, such as a variation needed to bring the project design into compliance with a building code, is mandatory and should be reviewed and processed differently than an elective change. Whether it is an elective change or a required change, change itself has effects on the project. These effects can impact cost, schedule, and organization, as reflected in our CMS process model. The project team should determine the potential impacts on the project, whether positive or negative, and take action to minimize negative change.

\section{EVALUATE CHANGE}

The third principle of the change management system is to evaluate change (Fig. 4). As a continuation of the previous principle, the purpose of evaluating change is to 


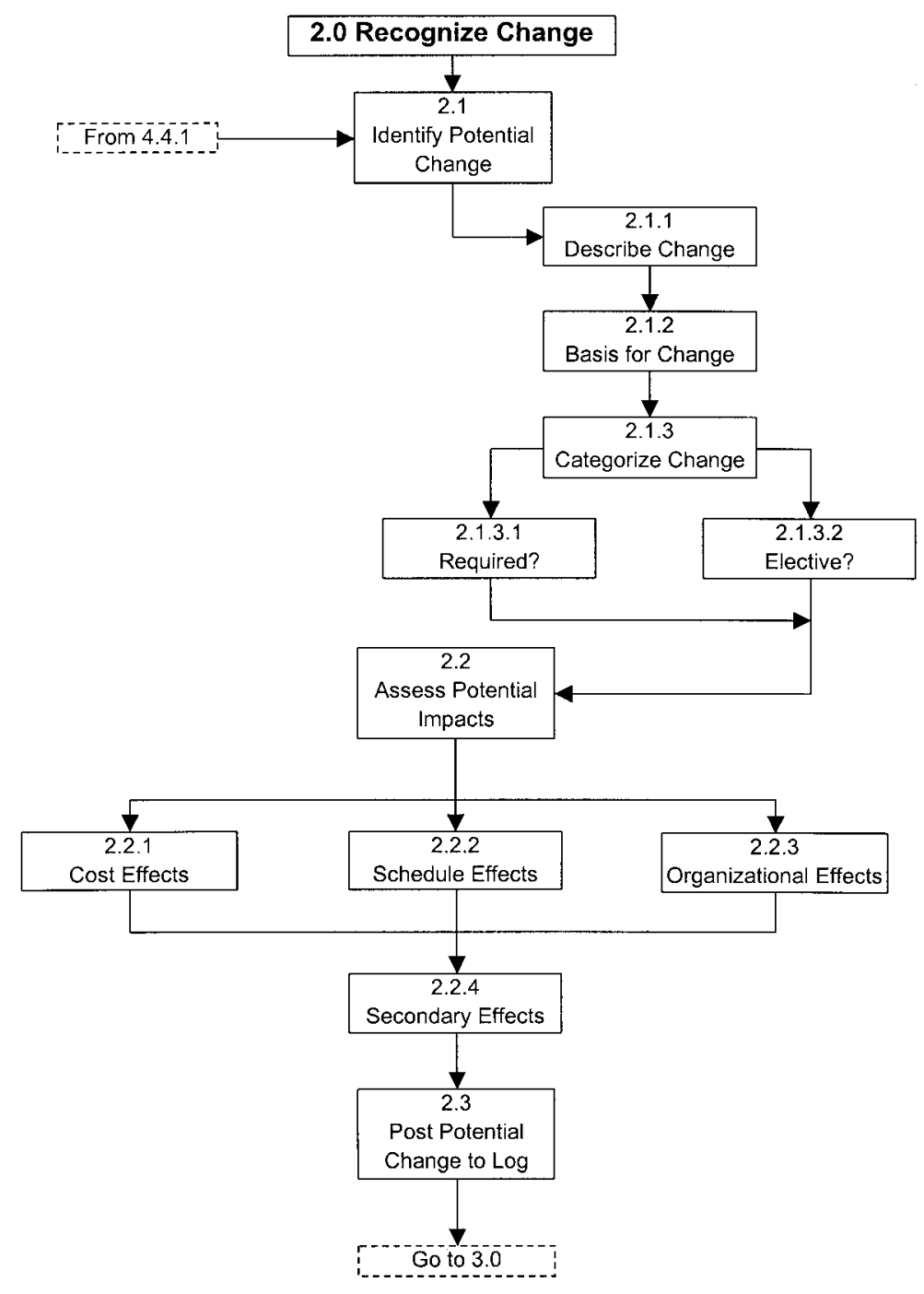

FIG. 3. Recognize Change

determine whether the management team should accept and implement the proposed change.

If the change is a high priority, the management team should determine the funding source for interim approval immediately, because any delay to the change will probably add to its cost. However, if the change is not that time sensitive, management should consider the proposal more deliberately to see whether the change is necessary. The reason for this reconsideration is that the function of the team is to maximize the profit of the project and to minimize the negative effects of change. In order to maximize the profit, the team has to screen any unnecessary changes or changes that do not contribute to the stated project goal and return on the investment.

An elective change means that management has an option to modify the original project goals, budget, or schedule. Such an elective change should be approved only if the benefits of that change substantially outweigh its costs. Some companies use an increasing benefit-to-cost $(\mathrm{B} / \mathrm{C})$ ratio scale as a guideline for approving such elective change. A change that is assessed later in a project should have a higher benefit-to-cost ratio threshold than an earlier change because of unforeseeable impact costs associated with late changes. Fig. 5 presents the conceptual benefitto-cost ratio graph. However, if the changes are prevented or cleverly converted to a beneficial change, the $\mathrm{B} / \mathrm{C}$ ratio would be much higher, because the time and cost impact of those changes are not allowed to grow consecutively and constantly throughout the project.

One key point for project team members to understand is that decisions (and projects) evolve. Team members should understand that change decisions could effectively serve as a checkpoint within the project. These checkpoints are necessary to minimize any mistake or any unnecessary change, and to maximize the profit or to achieve the defined scope of the project. Moreover, these checkpoints are important to the team, as the team has to decide whether they should continue to invest in the project. Any mistake that happens here will jeopardize the whole investment.

\section{IMPLEMENT CHANGE}

Implementing change is the next principle of the project change management system (Fig. 6). It is a very important 


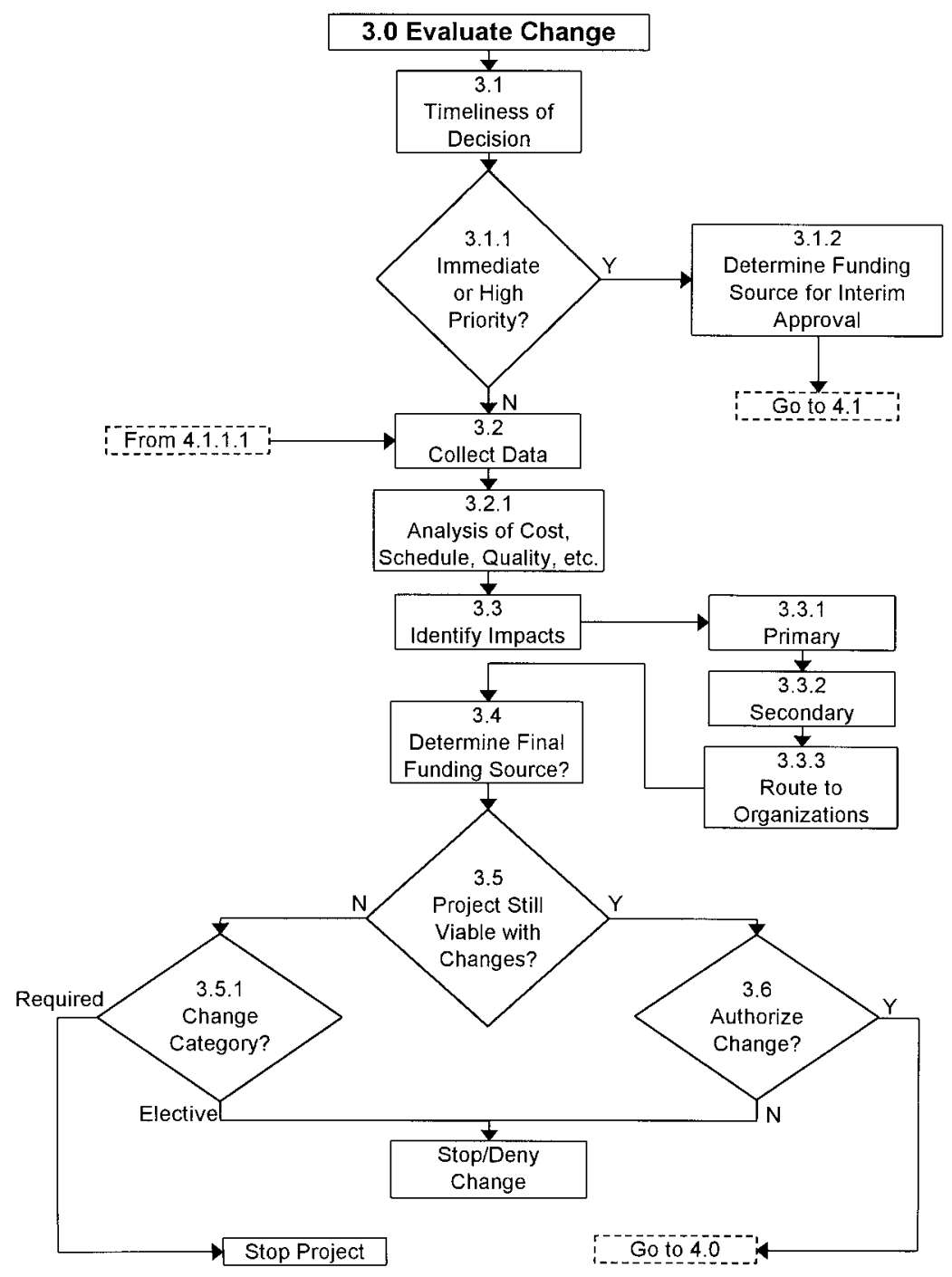

FIG. 4. Evaluate Change

step in the change project management, since this is the main reason to have the system. Despite its obvious need, the CII research team consistently found instances where there was no formal process to insure that the change was in fact implemented! The acceptance or rejection or change decisions are still not finished, of course, when the upper management has decided to accept the changes. Instead, the most important step is usually implementation.

In this principle, the approval of the changes is an authorization made by the upper management, and it should be high priority. This authorization should be granted after all parties - affected directly or indirectly — have been informed of the pending change. In many instances, changes will lead to other problems and additional changes, because management has failed to anticipate and contact other parties about such pending changes.

Monitoring implementation of changes not only requires monitoring the process of the implementation of a change, but also should be seen as an opportunity for the project team to resolve other difficulties that might be encountered to date on the project. Monitoring implemen- tation requires substantial documentation of a change so that disputed impacts can be resolved later or so lessons can be learned from the change.

\section{CONTINUOUSLY IMPROVE FROM LESSONS LEARNED}

The fifth and last principle of the change management system is to learn continuously from the mistakes that cause changes (Fig. 7). The main idea of this principle is to perform root causes and to evaluate the mistakes made so that errors can be systematically corrected. Such analyses should be openly discussed between the team members so that everyone will have a chance to understand the root causes of the changes.

Having the team members understand the root causes of change is important, since the experience of managing the change helps them prevent similar mistakes in the future. Project team members should take advantage of lessons learned in the past so that they also learn to think, approach, and manage problems in a proactive fashion. 


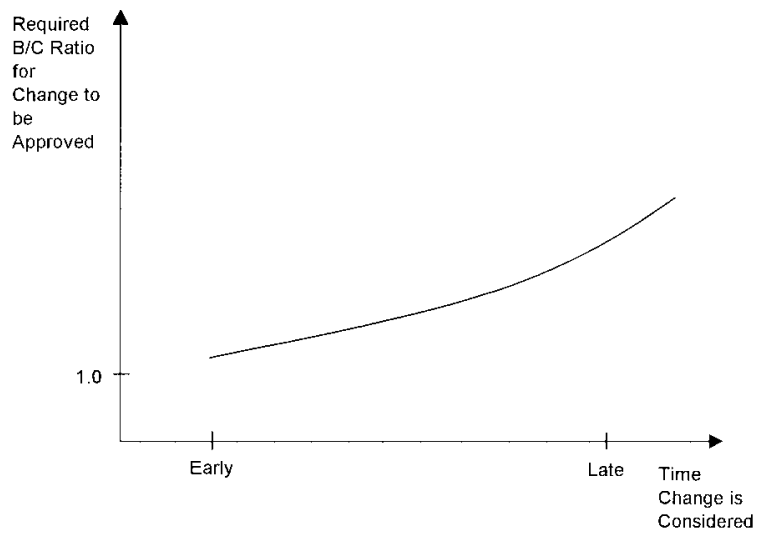

FIG. 5. Benefit-to-Cost Ratio Required for Elective Change

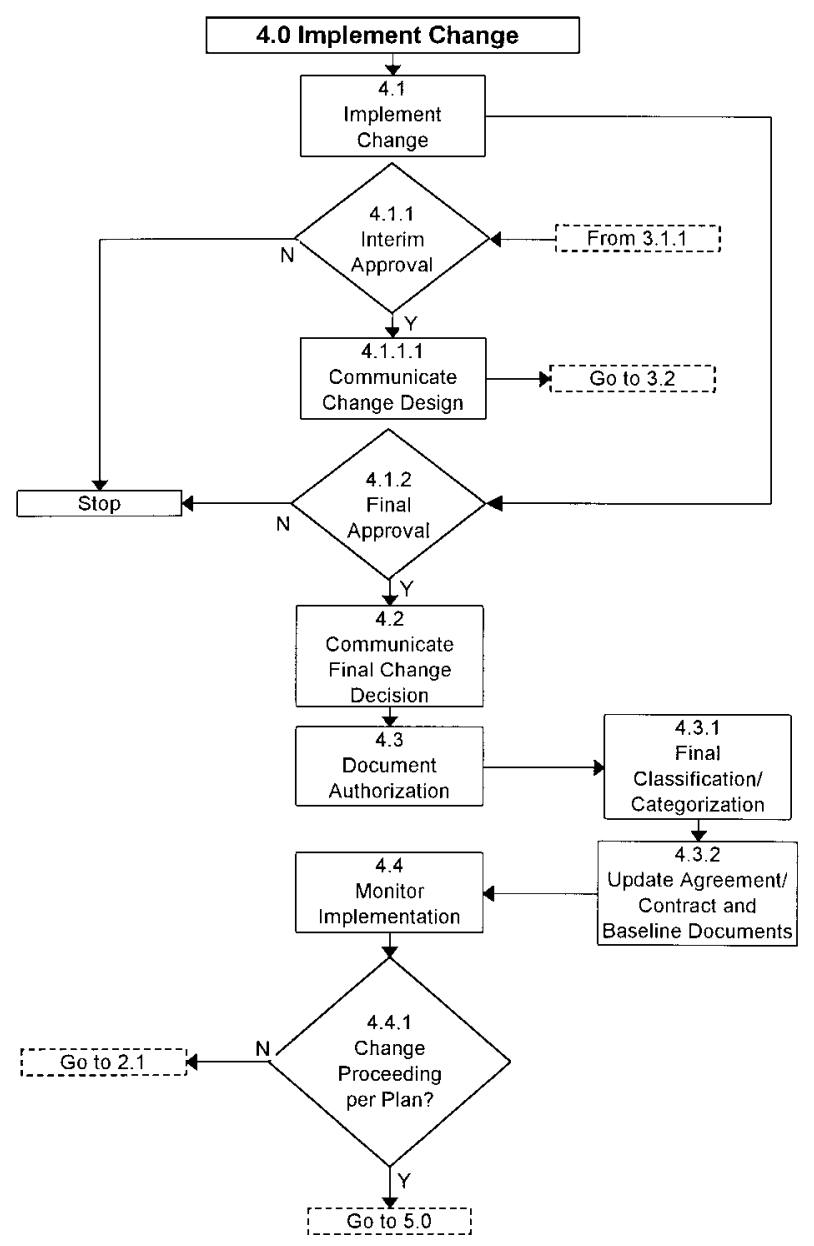

FIG. 6. Implement Change

\section{DISCUSSION}

The central idea of any change management system is to anticipate, recognize, evaluate, resolve, document, and learn from conflicts in ways that support the overall viability of the project. Learning from the mistakes and conflicts are important, because the team members can enrich and apply their experience in the future. The change management system outlined in this paper cannot be directly inserted into an organization without some adaptation. However, the principles and processes presented should

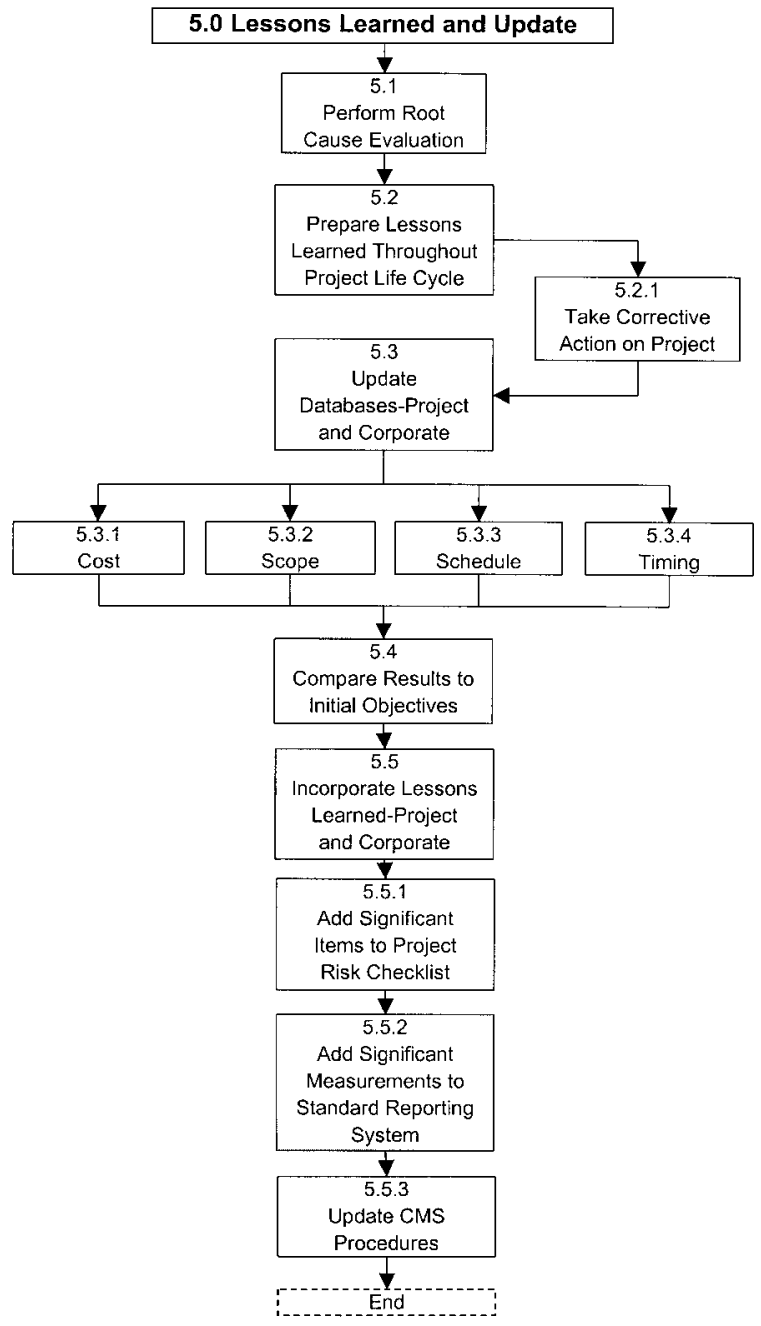

FIG. 7. Lessons Learned and Updated

be a reasonable starting point for many engineering-construction related companies trying to establish a project change management system.

\section{CONCLUSION}

The main goal of this paper was to introduce and explain a systematic change management system for projects. The change management system described is a two-level process model, with principles as the foundation, and management processes to implement those principles. By having a systematic way to deal with changes, the efficiency of project work and the likelihood of project success should increase.

\section{REFERENCES}

CII Project Change Management Research Team. (1994). Project change management, Construction Industry Institute, Austin, Tex. Huntoon, C. (1998). "Managing change." Proj. Mgmt. J., 29(3), 5-6. Ibbs, C. W. (1997). "Quantitative impacts of project change: size issues." J. Constr. Engrg. and Mgmt., ASCE, 123(3), 308-311.

Ibbs, C. W., Lee, S., and Li, M. (1998). "Fast-tracking's impact on project change." Proj. Mgmt. J., 29(4), 35-41. 
Kartam, N. (1996). "Making effective use of construction lessons learned in project life cycle." J. Constr. Engrg. and Mgmt., ASCE, 122(1), 14-21.

Mallak, L., Kurstedt Jr., H., and Patzak, G. (1997). "Planning for crises in project management." Proj. Mgmt. J., 28(2), 14-20.

Naoum, S. (1994). "Critical analysis of time and cost of management and traditional contracts." J. Constr. Engrg. and Mgmt., ASCE, 120(4), 687-705.

Pinto, J., and Kharbanda, O. (1995). "Project management and conflict resolution.” Proj. Mgmt. J., 26(4), 45-54.

Tiong, R. (1990). "Effective controls for large scale construction projects." Proj. Mgmt. J., 11(1), 32-42. 